\title{
Problems of welding in shipbuilding - an analytic-numerical assessment of the thermal cycle in haz with three dimensional heat source models in agreement with modelling rules
}

\author{
Part I \\ Theoretical basis of modelling and an analytical assessment \\ of heat sources models
}

Eugeniusz Ranatowski, Prof

University of Technology and Life Science, Bydgoszcz

ABSTRACT

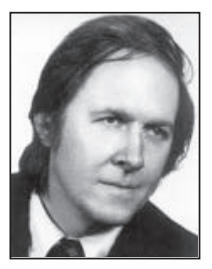

At the beginning of this paper a short characteristic of the methodology of classic RosenthalRykalin solution of temperature distribution during welding is provided. In the further part, the requirements concerning process modelling were presented, particularly with thermal processes taken into consideration.

Finally, the Cylindrical-Involution-Normal and Double-Ellipsoidal heat source models are presented.

Keywords:

\section{INTRODUCTION}

Classic solutions of Fourier -Kirchhoff (F-K) partial differential equation, describing heat distribution and leading to analytic definition of temperature fields during welding process, were first started by works of $\mathrm{R}$ ykalin and Rosenthal. The temperature fields and other related parameters were found with assuming the following simplifications and presumptions:

a) the analysis is limited to quasi-stationary state, stabilised temperature field

b) heat sources are described by: point, line or plane models

c) the material physical parameters are constant, temperature invariant

d) welded parts structure is homogenous with isotropic physical properties

e) there are no other inner heat sources during welding process

f) three basic geometrical bodies are introduced in respect to the geometry:

- the semi-infinitely extend solid

- the infinitely extended plate

- the infinitely extended rod.

The assumptions above were some necessary simplifications to get the solution but on the other hand affeted the preciseness of temperature field estimation. The necessary limitations are result of methods used for analytic calculation. The adopted methods mainly base on integral transform methods and Green's functions.

It should be said clearly that most of heat source analytical models as also solid material models are not adequate to presently used welding technologies, e.g. plasma stream, laser or an electron beam. In the aftermath of this, three-dimensional heat source model is introduced and also new relation Heat Source (HS) - Welded Material (WM) model is created.

Substantial imperfection of classic Rykalin's and Rosenthal's solution is a lack of taking into consideration the heat exchange at boundary surfaces.Another important problem is considering thermal process as linear, although in fact it's not linear.

\section{BASIC REQUIREMENTS CONCERNING MODELLING RULES}

Modelling is the process of fixing a computational model. The bottom line of any correct modelling procedure is defining the parameters characterising the ideology and process dimensions.

An estimation of physic phenomenon during welding process, practically results in examining reciprocal relations between extensive and intensive parameters. 
The transport process of extensive magnitudes requires estimation of intensive parameters during welding and is performed by using such procedures as transient Lagrangian or steady state Eulerian formulations of thermal cycle. We define an Eulerian (moving ) frame with origin at the centre of the source and co-ordinates $(\mathrm{x}, \mathrm{y}, \mathrm{z})-$ Fig. 1. For Cartesian co-ordinate system $\left(\mathrm{x}_{0}, \mathrm{y}_{0}, \mathrm{z}_{0}\right)$ which remains stationary for all time $\mathrm{t}$ and loading history, a Lagrangian co-ordinate reference is defined. Suppose a heat source is moving at a constant speed in the positive $\mathrm{x}_{0}$ direction.

The transformation from $\left(\mathrm{x}_{0}, \mathrm{y}_{0}, \mathrm{z}_{0}\right)$ to $(\mathrm{x}, \mathrm{y}, \mathrm{z})$ is given by: $\mathrm{x}=\mathrm{x}_{0}-\mathrm{vt}, \mathrm{y}=\mathrm{y}_{0}, \mathrm{z}=\mathrm{z}_{0}$.

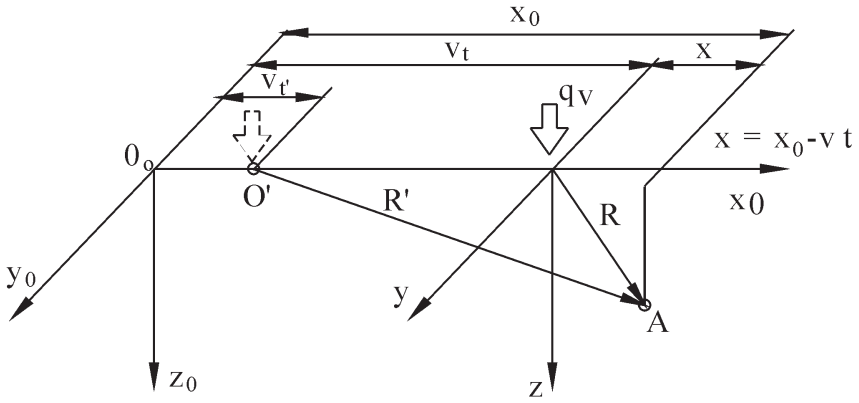

Fig. 1. Lagrangian and Eulerian co-ordinate reference

Specified phenomenon model is connected with presumption that the model represents the physic reality well enough. In addition, the characteristic feature of the model is ability to replace the actual object with the model, still committing transmitting the experimental results into actual research object.

Definition of theoretical structure of research object is performed with use of:

- physic model, describing the actual object

- mathematical model, being an equation or system of equations, describing processes together with boundary conditions, characteristic for given phenomenon.

Above mentioned statements are fundamentally in compliance with Fourier's observation - who stated in "Théorie analytique de la chaleur" that "...every phenomenon connected with heat depends on very little, general facts the way that every problem can be formulated using the language of mathematical analysis..." [2].

The basic physic laws are described mathematically , receiving first generation of mathematical models which are last modified (some of those modifications have empirical connections). In compliance with Riemann consolidations, real basic rules like heat flow, can occur for infinitely small magnitudes and must be defined as partial differential equations. Integration of such equations leads to settlements and rules for variables of space and time e.g. estimation of temperature distribution for a plate of optional thickness during welding. High conformity and quality of anticipating is obtained if definite phenomenon modelling rules are fulfilled.

Correct executing of research requires using the proper models and conditions with dependence on their likeness. Knowing the equations describing given process, for example heat flow according F-K equation the criterions and constants of similarity can be found.

If a given variable is marked $x_{i}$ in actual object and $\overline{x_{i}}$ in model object then the connection can be created:

$$
\frac{\mathrm{x}_{1}}{\overline{\overline{\mathrm{x}_{1}}}}=\mathrm{c}_{1}, \ldots, \frac{\mathrm{x}_{\mathrm{i}}}{\overline{\overline{\mathrm{x}_{\mathrm{i}}}}}=\mathrm{c}_{\mathrm{i}}, \ldots, \frac{\mathrm{x}_{\mathrm{n}}}{\overline{\mathrm{x}_{\mathrm{n}}}}=\mathrm{c}_{\mathrm{n}}
$$

Modelling scale is a transforming factor. Therefore the following relation can be given:
$\Phi\left(\mathrm{x}_{1}, \mathrm{x}_{2}, \mathrm{x}_{3} \ldots, \mathrm{x}_{\mathrm{n}}\right)=\Phi\left(\mathrm{c}_{1} \overline{\mathrm{x}}_{1}, \mathrm{c}_{2} \overline{\mathrm{x}}_{2}, \mathrm{c}_{3} \overline{\mathrm{x}}_{3} \ldots, \mathrm{c}_{\mathrm{n}} \overline{\mathrm{x}}_{\mathrm{n}}\right)$

For similar phenomenon there is a relation given:

$$
\Phi\left(\mathrm{x}_{1}, \mathrm{x}_{2}, \mathrm{x}_{3} \ldots, \mathrm{x}_{\mathrm{n}}\right)=\Phi\left(\overline{\mathrm{x}}_{1}, \overline{\mathrm{x}}_{2}, \overline{\mathrm{x}}_{3} \ldots, \overline{\mathrm{x}}_{\mathrm{n}}\right)
$$

Equation (3) is fulfilled if $c_{n}$ is in conformity with:

$$
\begin{gathered}
\Phi\left(\mathrm{c}_{1}, \mathrm{c}_{2}, \mathrm{c}_{3} \ldots, \mathrm{c}_{\mathrm{n}}\right)=1 \\
\Phi\left(\mathrm{c}_{1}, \mathrm{c}_{2}, \mathrm{c}_{3}, \ldots, \mathrm{c}_{\mathrm{n}}\right)= \\
=\frac{\Phi\left(\mathrm{c}_{1} \overline{\mathrm{x}_{1}}, \mathrm{c}_{2} \overline{\mathrm{x}_{2}}, \mathrm{c}_{3} \overline{\mathrm{x}_{3}}, \ldots, \mathrm{c}_{\mathrm{n}} \overline{\mathrm{x}_{\mathrm{n}}}\right)}{\Phi\left(\overline{\mathrm{x}_{1}}, \overline{\mathrm{x}_{2}}, \overline{\mathrm{x}_{3}}, \ldots, \overline{\mathrm{x}_{\mathrm{n}}}\right)}
\end{gathered}
$$

In compliance with Federman' s settlements it's known that if a number of variables used in experiment is equal to $n$ and a few of them are independent $\mathrm{k}<\mathrm{n}$, then there are $(\mathrm{n}-\mathrm{k})$ equations expressed by modelling scale $c_{i}$. Therefore a few of dimensionless numbers may be proposed by an experimenter and be the constants of similarity The remaining ones are described by dimensionless numbers and Federmans settlements and are called similarity criterions. The indispensable conditions for similarity existing between the models and actual objects is describing the happening physic processes by:

- the same differential equations with appropriate boundary conditions

the similarity criterions verification.

Let's take into consideration F-K partial dif ferential heat flow equation as a starting point - for stationary co-ordinates system $\mathrm{x}_{0}, \mathrm{y}_{0}, \mathrm{z}_{0}$ :

$$
\operatorname{div}(\lambda \cdot \operatorname{grad} T)-c_{p} \cdot \rho \frac{\partial T}{\partial t}=-q_{v}\left(x_{0}, y_{0}, z_{0}, t\right)
$$

The classic Rykalin's and Rosenthal's solutions assume that physic parameters describing the process model are constant whereas they are in fact non-linear for real welding system as a result of dependence on temperature.

According to that we have the following characteristic [following equations (1) - (4)]:

\begin{tabular}{|c|c|}
\hline Process model & Actual welding system \\
\hline$\lambda=$ const & $\lambda(T) \neq$ const \\
\hline$c_{p}=$ const & $c_{p}(T) \neq$ const \\
\hline$\rho=$ const & $\rho(T) \neq$ const \\
\hline
\end{tabular}

$$
\begin{gathered}
\frac{\lambda(\mathrm{T})}{\bar{\lambda}}=\mathrm{c}_{1} ; \frac{\mathrm{c}_{\mathrm{p}}(\mathrm{T})}{\overline{\mathrm{c}}_{\mathrm{p}}}=\mathrm{c}_{2} ; \frac{\rho(\mathrm{T})}{\bar{\rho}}=\mathrm{c}_{3} \\
\mathrm{c}_{1} \neq \mathrm{c}_{2} \neq \mathrm{c}_{3} \\
\Phi\left(\mathrm{c}_{1}, \mathrm{c}_{2}, \mathrm{c}_{3}\right) \neq 1
\end{gathered}
$$

Moreover, $\mathrm{q}_{\mathrm{v}}$ doesn't fulfil geometric similarity condition for majority of contemporary welding methods like arc welding, GTA, GMA, plasma stream and others, assuming point, line or plain heat source model

Considering possibility of universal shape modelling and to fulfil conditions (4), (5), two main models are considered: Cylindrical-Involution-Normal (C-I-N) [3] and The Double Ellipsoidal Configuration of Source (D-E) [4]. Both models represent effective extended abilities of 3-dimensional heat distribution. The model that previously was used is the Gaussian surface flux distribution model: 


$$
\mathrm{q}_{\mathrm{v}}=\frac{\mathrm{Q} \cdot \mathrm{k}}{\pi \cdot \mathrm{s}} \exp \left[-\mathrm{k}\left(\mathrm{x}^{2}+\mathrm{y}^{2}\right)\right] \cdot[1-\mathrm{u}(\mathrm{z}-\mathrm{s})]
$$

Unfortunately this one does not reflect heat power input change for "z" variable. For exampleWei and Shian' constituted that under high-intensity laser beam welding the incident energy rate distribution is assumed to be Gaussian distribution and HS model is idealised by a paraboloid of revolution. This is one of main reasons why two more accurate models are implemented.

\section{THE CHARACTERISTIC OF HEAT SOURCE MODELS}

The mathematical expression of the cylindrical-involutionnormal C-I-N model is:

$\mathrm{q}_{\mathrm{v}}=\mathrm{q}_{\mathrm{vMAX}} \cdot \exp \left[-\mathrm{k}\left(\mathrm{x}^{2}+\mathrm{y}^{2}\right)-\mathrm{K}_{\mathrm{z}} \cdot \mathrm{z}\right] \cdot[1-\mathrm{u}(\mathrm{z}-\mathrm{s})]$

As it is seen " $\mathrm{z}$ " variable is not squared in contrast to other variables. This is an intentional purpose of this model to let it be easily integrated when using integral transformation method.

D-E model doesn't have this feature which makes it difficult to achieve precise solution while transforming.

Let's calculate $\mathrm{q}_{\mathrm{vMAX}}$ factor for C-I-N. Provided that the following condition must be preserved:

$$
\begin{gathered}
\mathrm{Q}=\int_{0}^{\infty} \int_{-\infty}^{\infty} \int_{-\infty}^{\infty} \mathrm{q}_{\mathrm{vMAX}} \cdot \exp \left[-\mathrm{k}\left(\mathrm{x}^{2}+\mathrm{y}^{2}\right)-\mathrm{K}_{\mathrm{Z}} \cdot \mathrm{z}\right] \\
\cdot[1-\mathrm{u}(\mathrm{z}-\mathrm{s})] \mathrm{dxdydz}
\end{gathered}
$$

and after integrate operation upon several variables we obtain:

$$
\begin{array}{r}
\mathrm{Q}=\int_{0}^{\infty} \int_{-\infty}^{\infty} \frac{\sqrt{\pi}}{\sqrt{\mathrm{k}}} \mathrm{q}_{\mathrm{vMAX}} \cdot \exp \left(-\mathrm{ky}^{2}-\mathrm{K}_{\mathrm{z}} \cdot \mathrm{z}\right) \\
\cdot(1-\mathrm{u}(\mathrm{z}-\mathrm{s})) \mathrm{dydz} \\
\mathrm{Q}=\int_{0}^{\infty} \frac{\pi}{\mathrm{k}} \mathrm{q}_{\mathrm{vMAX}} \cdot \exp \left(-\mathrm{K}_{\mathrm{z}} \cdot \mathrm{z}\right) \cdot[1-\mathrm{u}(\mathrm{z}-\mathrm{s})] \mathrm{dz} \\
\mathrm{Q}=-\frac{\pi}{\mathrm{k} \cdot \mathrm{K}_{\mathrm{z}}} \mathrm{q}_{\mathrm{vMAX}} \cdot \exp \left(-\mathrm{K}_{\mathrm{z}} \cdot \mathrm{s}\right)-\frac{-\pi}{\mathrm{k} \cdot \mathrm{K}_{\mathrm{z}}} \mathrm{q}_{\mathrm{vMAX}}
\end{array}
$$

thus:

$$
\mathrm{q}_{\mathrm{vMAX}}=\frac{\mathrm{Q}}{\pi \cdot\left[1-\exp \left(-\mathrm{K}_{\mathrm{z}} \cdot \mathrm{s}\right)\right]} \cdot \mathrm{k} \cdot \mathrm{K}_{\mathrm{z}}
$$
and finally:

$$
\begin{gathered}
\mathrm{q}_{\mathrm{v}}=\frac{\mathrm{Q}}{\pi \cdot\left[1-\exp \left(-\mathrm{K}_{\mathrm{z}} \cdot \mathrm{s}\right)\right]} \cdot \mathrm{k} \cdot \mathrm{K}_{\mathrm{z}} \cdot \\
\cdot \exp \left[-\mathrm{k}\left(\mathrm{x}^{2}+\mathrm{y}^{2}\right)-\mathrm{K}_{\mathrm{Z}} \cdot \mathrm{z}\right] \cdot[1-\mathrm{u}(\mathrm{z}-\mathrm{s})]
\end{gathered}
$$
Fig. 2.

The $[1-(u(z-s))]$ factor illustrates that $\mathrm{q}_{\mathrm{v}}=0$ if $\mathrm{z}>\mathrm{s}$, see

By changing: $\mathrm{s}$, $\mathrm{k}$ and $\mathrm{K}$ factors, $\mathrm{C}-\mathrm{I}-\mathrm{N}$ model can represent all presently used heat sources.

Let's use equation (12) to analyse the shape of the surface that limits the volume of ef fective C-I-N af fect. Surfaces of constant values can be obtained by comparing:

$$
\begin{gathered}
\mathrm{q}_{\mathrm{v}}=\mathrm{q}_{\mathrm{vMAX}} \cdot \exp \left[-\mathrm{k}\left(\left(\mathrm{x}^{2}+\mathrm{y}^{2}\right)-\mathrm{K}_{\mathrm{z}} \cdot \mathrm{z}\right)\right. \\
\cdot(1-\mathrm{u}(\mathrm{z}-\mathrm{s}))]=\mathrm{const}
\end{gathered}
$$

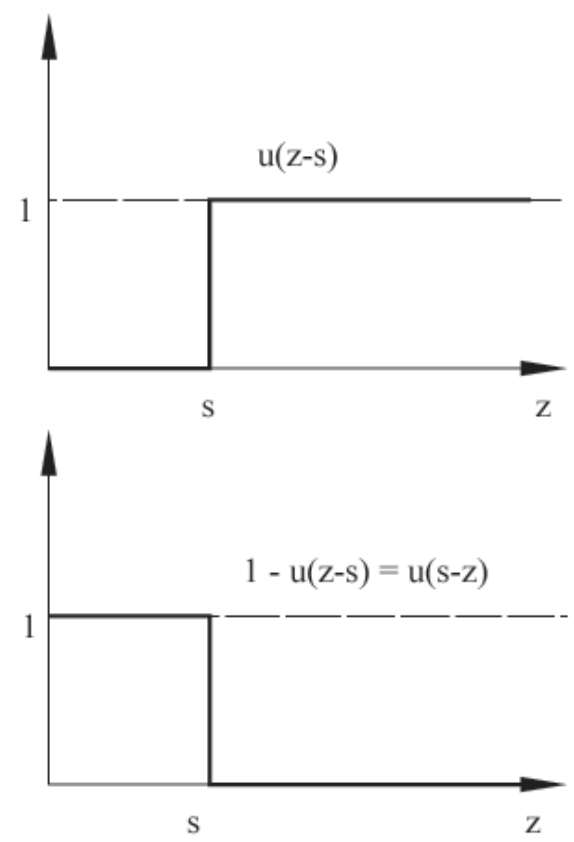

Fig. 2. Heaviside's functions

where:

$$
\mathrm{q}_{\mathrm{vMAX}}=\frac{\mathrm{k} \cdot \mathrm{K}_{\mathrm{z}} \cdot \mathrm{Q}}{\pi \cdot\left[1-\exp \left(-\mathrm{K}_{\mathrm{z}} \cdot \mathrm{s}\right)\right]}
$$

(according to (11e).

Presuming $\mathrm{z}<\mathrm{s}$ we receive:

$$
\begin{gathered}
\exp \left[-\mathrm{k} \cdot\left(\mathrm{x}^{2}+\mathrm{y}^{2}\right)-\mathrm{K}_{\mathrm{z}} \mathrm{z}\right]=\frac{\text { const }}{\mathrm{q}_{\mathrm{vMAX}}}=A \\
-\mathrm{k} \cdot\left(\mathrm{x}^{2}+\mathrm{y}^{2}\right)-\mathrm{K}_{\mathrm{z}} \cdot \mathrm{z}=\ln (\mathrm{A})=-\mathrm{B} \\
\mathrm{z}=\frac{\mathrm{B}-\mathrm{k} \cdot\left(\mathrm{x}^{2}+\mathrm{y}^{2}\right)}{\mathrm{K}_{\mathrm{z}}}
\end{gathered}
$$

Solution (14) gives a family of paraboloids of revolution. Taking into consideration $[1-\mathrm{u}(\mathrm{z}-\mathrm{s})]$ factor, it is obvious that some of the paraboloids may be "cut". A few examples of paraboloids are shown in Fig. 3. All of them have the same height $\mathrm{h}=\mathrm{s}$.
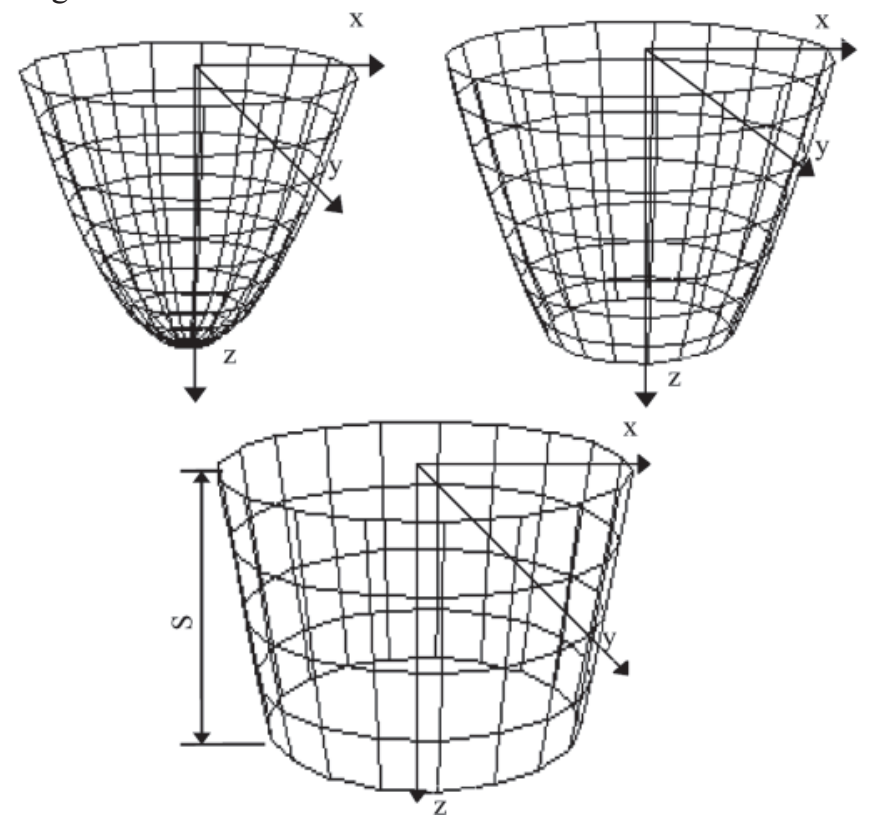

Fig. 3. Examples of the paraboloids of constant values of $q_{v}$ 
The paraboloid that limits the volume of ef fective input affect can be obtained using R ykalin's suggestion that HS power loses its effectivity when:

$$
\begin{gathered}
\mathrm{q}_{\mathrm{vMAX}} \cdot \exp \left[-\mathrm{k} \cdot\left(\mathrm{x}^{2}+\mathrm{y}^{2}\right)-\mathrm{K}_{\mathrm{z}} \cdot \mathrm{z}\right]=0.05 \mathrm{q}_{\mathrm{vMAX}} \\
-\mathrm{k} \cdot\left(\mathrm{x}^{2}+\mathrm{y}^{2}\right)-\mathrm{K}_{\mathrm{z}} \cdot \mathrm{z}=3 \\
\mathrm{z}=\frac{3}{\mathrm{~K}_{\mathrm{z}}}-\frac{\mathrm{k}}{\mathrm{K}_{\mathrm{z}}} \cdot\left(\mathrm{x}^{2}+\mathrm{y}^{2}\right) \quad \mathrm{z} \leq \mathrm{s}
\end{gathered}
$$

Equation (15) is an expression that describes effective input affect volume. In dependence on $\mathrm{h}=3 / \mathrm{K}$ value, the mentioned paraboloids can be more or less slim - see Fig. 4. At extreme conditions one can obtain several, well known heat source models like:

a) for $\mathrm{K}_{\mathrm{z}} \rightarrow 0, \mathrm{k} \neq 0-$ cylinder with height $=\mathrm{s}-$ disc heat source

b) for $\mathrm{K}_{\mathrm{z}} \rightarrow \infty, \mathrm{s} \rightarrow 0, \mathrm{k} \neq 0$ - surface heat source.
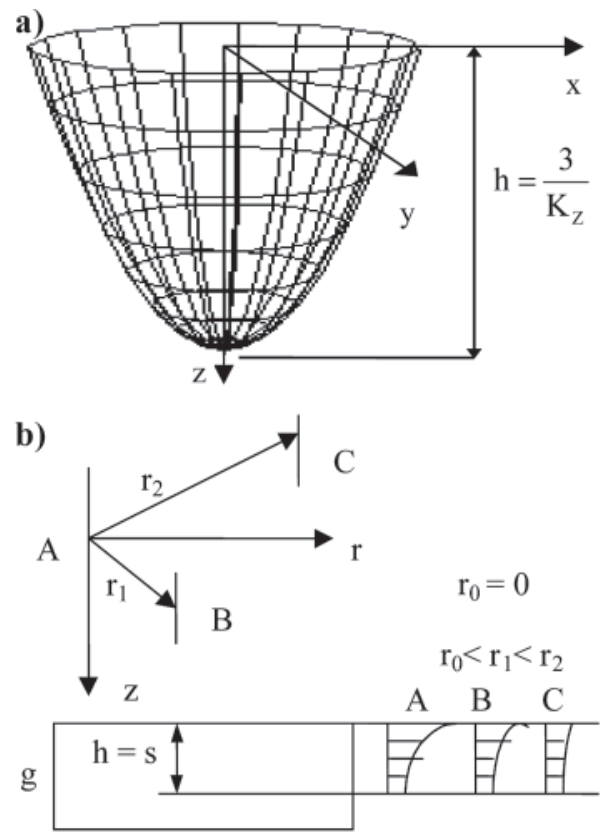

Fig. 4. The paraboloid limiting C-I-N effective input power volume (a) and power in dependence on distance from centre and depth

Possibility of changing $\mathrm{K}_{\mathrm{z}}, \mathrm{k}$, $\mathrm{s}$ and Heaviside' s function $\mathrm{u}(\mathrm{z}-\mathrm{s})$ values makes $\mathrm{C}-\mathrm{I}-\mathrm{N}$ heat source a universal one.

The Double Ellipsoidal heat source model (D-E) (Fig. 5) established by J. Goldak [4] et al. has the following form:

$$
\left.\begin{array}{c}
\mathrm{q}_{\mathrm{vf}}=\frac{\mathrm{f}_{\mathrm{f}} \cdot 6 \cdot \sqrt{3} \cdot \mathrm{Q}}{\mathrm{a} \cdot \mathrm{b} \cdot \mathrm{c} \cdot \pi \cdot \sqrt{\pi}} \cdot \\
\cdot \exp \left[-3\left[\left(\frac{\mathrm{x}}{\mathrm{a}_{1}}\right)^{2}+\left(\frac{\mathrm{y}}{\mathrm{b}}\right)^{2}+\left(\frac{\mathrm{z}}{\mathrm{c}}\right)^{2}\right]\right] \\
\mathrm{q}_{\mathrm{vf}}=\frac{\mathrm{f}_{\mathrm{r}} \cdot 6 \cdot \sqrt{3} \cdot \mathrm{Q}}{\mathrm{a} \cdot \mathrm{b} \cdot \mathrm{c} \cdot \pi \cdot \sqrt{\pi}} \cdot \exp \left[-3\left[\left(\frac{\mathrm{x}}{\mathrm{a}_{1}}\right)^{2}+\left(\frac{\mathrm{y}}{\mathrm{b}}\right)^{2}+\left(\frac{\mathrm{z}}{\mathrm{c}}\right)^{2}\right]\right] \\
\mathrm{f}_{\mathrm{r}}+\mathrm{f}_{\mathrm{f}}=2
\end{array}\right]
$$

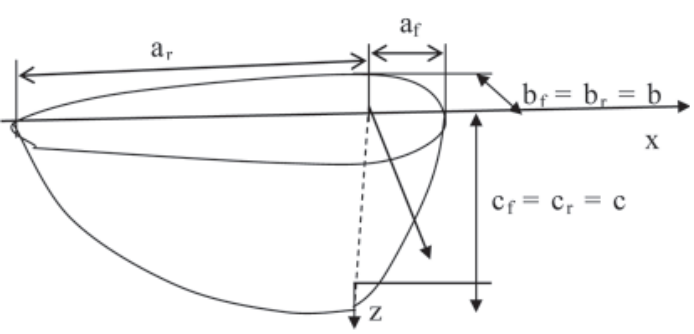

Fig. 5. The Double Ellipsoidal configuration of Heat Source model

D-E arrangement of volumetric heat sources is used for moving welding heat source of deep - penetrating surfacing or butt welds. The front half of the source is the quadrant of one ellipsoidal source, and the rear half is the quadrant of another ellipsoid. According to Godak [4] et al. some peculiar big pressure should be exerted on models, which are the combination of two or more usual heat source models, in order to effectively reflect the actual welding process. The structure of equation (16), which is an excellent one for numerical estimation of thermal cycles, has a few inconveniences when used for about finding analytic solution from methods described in this investigation. However, some estimation can be done as it is worthwhile to make some efforts, in order to obtain the necessary solution.

The adopted C-I-N model is favourable for simulation of welding process of high concentrated eneigy source used, like laser beam welding or electron beam welding. This one may also be used for the simulation of arc welding process.

\section{CONCLUSIONS}

Base on the fact that substantial imperfection of Rosenthak' and Rykalin's solutions relies on:

- considering thermal process as linear

- lack of taking into study the heat exchange at boundary surface,

most of heat source analytical models and solid material models are not adequate to presently used welding methods, there are established the basic requirements which concern modelling rules of welding process.

It is constituted that the indispensable conditions for similarity existing between the actual object and model describe the happening physic process by:

- the same differential equations with appropriate boundary conditions,

- the similarity criterions verification.

In order to fulfill above conditions, at first two heat source models are considered: C-I-N and D-E which represent effective extended abilities of 3 - dimentional heat distribution.

\section{NOMENCLATURE}

$\mathrm{T}-$

$\lambda-$ thermal conductivity, $\left[\mathrm{W} \mathrm{cm} \mathrm{cm}^{-1} \mathrm{~K}^{-1}\right]$

$\mathrm{c}_{\mathrm{p}} \quad-$ specific heat, $\left[\mathrm{J} \mathrm{kg}^{-1} \mathrm{~K}^{-1}\right]$

$\rho$ - mass density, $\left[\mathrm{kg} \mathrm{cm}^{-3}\right]$

$\mathrm{t}$ - time, [sec]

$\mathrm{q}_{\mathrm{v}} \quad-$ power input in volume, $\left[\mathrm{W} \mathrm{cm}^{-3}\right]$

Q $\quad-$ net power received by the weldment, [W]

$\mathrm{k}$ - $\quad$ a factor designating the HS concentration, $\left[\mathrm{cm}^{-2}\right]$

$\mathrm{s} \quad-$ HS penetration depth, $[\mathrm{cm}]$

$\mathrm{u}(\mathrm{z}-\mathrm{s})$ - Heaviside's function

$a_{f}, b_{f}, c_{f}, a_{r}, b_{r}, c_{r}-$ ellipsoids semiaxes, [cm]

$\mathrm{f}_{\mathrm{r}}, \mathrm{f}_{\mathrm{f}} \quad-$ fraction of heat deposits in front and rear quadrants

$\mathrm{q}_{\mathrm{vf}}, \mathrm{q}_{\mathrm{vr}} \quad$ - power density distribution inside the front and rear quadrants respectively, $\left[\mathrm{W} \mathrm{cm}^{-3}\right]$ 


\author{
$\mathrm{c}_{\mathrm{i}}-\quad$ modelling scale \\ - involution factor of HS, $\left[\mathrm{cm}^{-1}\right]$ \\ HAZ - Heat affected Zone \\ C-I-N - Cylindrical-Involution-Normal heat source \\ model \\ D-E - Double-Ellipsoidal heat source model \\ HS - Heat Source
}

BIBLIOGRAPHY

1. Lindgren L. E.: Journal of Thermal Stresses. Part 1. 2001. 24, pp. 141-192

2. Gårding L.: Encounter with mathematics. Springer-Verlag New York Inc. Copyright for Polish edition by PWN. Warsaw. 1993. pp. 278-279

3. Ranatowski E., Poćwiardowski A.: in' Mathematical modelling of weld phenomena 4' (ed. H. Cejrak). IoM Comunications. London. 1998. pp. 379-395
4. Goldak J. et al.: Metalurgical Transactions B. 1984. Vol. 15B. pp. 299-305

5. Wei P. S., Shian M. D.: Journal of Heat Transfer. 1993. Vol. 115. pp. 848-856.

\section{CONTACT WITH THE AUTHOR}

Prof. Ranatowski Eugeniusz

Faculty of Mechanical Engineerig, University of Technology and Life Science, Prof. S. Kaliskiego 7

85-763 Bydgoszcz, POLAND

e-mail: ranatow@utp.edu.pl 